\title{
Impact of postoperative major complications on long-term survival after radical resection of gastric cancer
}

Peng Yuan ${ }^{1 \dagger}$, Zhouqiao $\mathrm{Wu}^{2 \dagger}$, Ziyu $\mathrm{Li}^{2 \dagger}$, Zhaode $\mathrm{Bu}^{2}$, Aiwen $\mathrm{Wu}^{2}$, Xiaojiang $\mathrm{Wu}^{2}$, Lianhai Zhang ${ }^{2}$, Jinyao Shi ${ }^{2}$ and Jiafu $\mathrm{Ji}^{2^{*}}$ (i)

\begin{abstract}
Background: This study was designed to evaluate the impact of postoperative major complications on long-term survival following curative gastrectomy.

Methods: This retrospective study included 239 patients with gastric cancer undergoing gastrectomy at the Beijing Cancer Hospital from February 2012 to January 2013. Survival curves were compared between patients with major complications ( $\mathrm{mC}$ group) and those without major complications ( $\mathrm{NmC}$ group). Multivariate analysis was conducted to identify independent prognostic factors.

Results: Postoperative complication and mortality rates were 24.7 and $0.8 \%$, respectively. The severity of complications was graded in accordance with the Clavien-Dindo classification. The incidence of minor complications (grades I-II) and major complications (grades III-V) was 9.2 and 15.5\%, respectively. The 3-year overall survival (OS) and disease-free survival (DFS) rates were better in the NmC group than in the $\mathrm{mC}$ group $(p=0.014, p=0.013)$. Multivariate analysis identified major complications as an independent prognostic factor for OS and DFS. After stratification by pathological stage, this trend was also observed in stage II patients.

Conclusions: Postoperative major complications adversely affect OS and DFS. The prevention and early diagnosis of complications are essential to minimize the negative effects of complications on surgical safety and long-term patient survival.
\end{abstract}

Keywords: Gastric cancer, Complications, Clavien-Dindo classification, Survival

\section{Background}

Recent developments in the field of anti-cancer treatment have decreased cancer-related mortality [1]. Surgical resection remains the gold-standard treatment for gastric cancer. In the era of modern surgery, perioperative mortality and reoperation rates after gastric cancer have decreased to low levels [2]. However, the rate of postoperative complications remains unsatisfactory, varying from 18.3 to $36 \%$ [3-5]. Postoperative complications, particularly surgical complications, significantly prolong hospital stay and medical

\footnotetext{
* Correspondence: jijiafu@hsc.pku.edu.cn

†Peng Yuan, Zhouqiao Wu and Ziyu Li contributed equally to this work ${ }^{2}$ Key Laboratory of Carcinogenesis and Translational Research (Ministry of Education), Department of Gastrointestinal Cancer Center Surgery, Peking University Cancer Hospital \& Institute, \#52, Fucheng Road, Haidian, Beijing, People's Republic of China

Full list of author information is available at the end of the article
}

expenditure and have become major causes of postoperative short-term mortality.

Recent data have suggested that patients who suffer from complications have poorer long-term survival outcomes. The underlying reason for this trend remains to be established [6-9]. A major limitation of previous study is that most of those data were retrospectively collected, and complications are often diagnosed by different doctors. Such heterogeneity inevitably increases the amount of record bias, which may influence the analysis. Another pitfall is the failure of attending physicians to evaluate the severity of postoperative complications, which compromises a detailed analysis of the results. To this end, we analyzed data collected at our institution for cases seen during the period from 2012 to 2013. During that period, all clinical complication data were recorded and classified

(c) The Author(s). 2019 Open Access This article is distributed under the terms of the Creative Commons Attribution 4.0 International License (http://creativecommons.org/licenses/by/4.0/), which permits unrestricted use, distribution, and 
by a single doctor (chief resident) who was familiar with all cases and responsible for the quality control of medical records during that period. All data about treatment decision making was validated by the Multidisciplinary team (MDT) every Friday morning. The aim of this study was to investigate the impact of postoperative complications on long-term survival after radical resection of gastric cancer, to evaluate the severity of complications according to the Clavien-Dindo scoring system, and analyze the impact of major and minor complications.

\section{Methods}

This is a retrospective study that investigated the effects of surgical complications. We enrolled 239 consecutive patients who had previously undergone gastrectomy with D2 lymph node dissection at the Beijing Cancer Hospital from February 2012 to January 2013. All patients recruited to our study were diagnosed with gastric adenocarcinoma, as confirmed by endoscopy and histology. Patients with any other malignancy were excluded.

Patient characteristics and clinical records were obtained from the HIS medical system at our institution. For each patient, the following clinical data were collected and analyzed: patient factors (age, sex, Body mass index (BMI), comorbidity, and prior history of abdominal surgery), tumor pathology, treatment factors (operation time, combined organ resection, blood loss, preoperative chemotherapy, extent of resection, and surgical type), and the length of hospital stay. Tumors were staged in accordance with the Union for International Cancer Control Classification System (7th edition). According to this system, patients

Table 1 Complications and the corresponding diagnostic criteria

\begin{tabular}{|c|c|}
\hline Complication & Diagnostic notes \\
\hline $\begin{array}{l}\text { Anastomotic } \\
\text { leakage }\end{array}$ & $\begin{array}{l}\text { Leakage confirmed by angiography or bowel } \\
\text { content seen in drainage }\end{array}$ \\
\hline $\begin{array}{l}\text { Anastomotic } \\
\text { bleeding }\end{array}$ & $\begin{array}{l}\text { Continuous blood content seen in gastric tube } \\
\text { and continuous decreasing hemoglobin level, } \\
\text { within } 24 \text { h after surgery }\end{array}$ \\
\hline $\begin{array}{l}\text { Abdominal } \\
\text { bleeding }\end{array}$ & $\begin{array}{l}\text { Continuous blood content seen in drainage and } \\
\text { continuous decreasing hemoglobin level, within } \\
24 \mathrm{~h} \text { after surgery }\end{array}$ \\
\hline $\begin{array}{l}\text { Surgical site } \\
\text { infection }\end{array}$ & Wound abscess with clinical symptoms \\
\hline $\begin{array}{l}\text { Bowel } \\
\text { obstruction }\end{array}$ & Clinical symptoms with radiographic confirmation \\
\hline $\begin{array}{l}\text { Abdominal } \\
\text { effusion }\end{array}$ & Continuous high abdominal drainage output \\
\hline Pancreatitis & $\begin{array}{l}\text { Drain output of any measurable volume of fluid on } \\
\text { or after postoperative day } 3 \text { with an amylase content } \\
\text { greater than } 3 \text { times the serum amylase activity }\end{array}$ \\
\hline $\begin{array}{l}\text { Bowel } \\
\text { preformation }\end{array}$ & Intraoperative or radiographic confirmation \\
\hline Pneumonia & Clinical symptoms with radiographic confirmation \\
\hline
\end{tabular}

receiving neo-adjuvant chemotherapy who respond with a complete pathological response following surgery are classified as stage 0 .

Postoperative outcome and details of any resulting complications were also collected from the electronic medical records. The complications recorded and corresponding diagnostic criteria are listed in Table 1. All complications

Table 2 Characteristics of 239 patients undergoing gastrectomy

\begin{tabular}{|c|c|}
\hline Variables & Total $(n=239)$ \\
\hline Age & $59.0 \pm 12.0$ \\
\hline \multicolumn{2}{|l|}{ Sex } \\
\hline Male & $166(69.5 \%)$ \\
\hline Female & $73(30.5 \%)$ \\
\hline \multicolumn{2}{|l|}{ Age } \\
\hline$\leq 55$ & $71(39.4)$ \\
\hline$>55$ & $109(60.6)$ \\
\hline BMI (kg/m2) & $22.6 \pm 3.4$ \\
\hline Operation time (min) & $220 \pm 63.1$ \\
\hline \multicolumn{2}{|l|}{ Resection type } \\
\hline Subtotal & $113(47.3 \%)$ \\
\hline Total & $126(52.7 \%)$ \\
\hline \multicolumn{2}{|l|}{ Combined organ resection } \\
\hline Yes & $10(4.2 \%)$ \\
\hline No & 229 (95.8\%) \\
\hline \multicolumn{2}{|l|}{ Neoadjuvant chemotherapy } \\
\hline Yes & $86(36.0 \%)$ \\
\hline No & $153(64.0 \%)$ \\
\hline \multicolumn{2}{|l|}{ Surgery type } \\
\hline Open & $208(87.0 \%)$ \\
\hline Laparoscope & $31(13.0 \%)$ \\
\hline \multicolumn{2}{|l|}{ Comorbidity Diabetes } \\
\hline Yes & $18(7.5 \%)$ \\
\hline No & $221(92.5 \%)$ \\
\hline \multicolumn{2}{|l|}{ Cardiovascular Diseases } \\
\hline Yes & $46(19.2 \%)$ \\
\hline No & $193(80.8 \%)$ \\
\hline \multicolumn{2}{|l|}{ Prior abdominal surgery } \\
\hline Yes & $31(13.0 \%)$ \\
\hline No & $208(87.0 \%)$ \\
\hline \multicolumn{2}{|l|}{ TNM staging (AJCC 7th) } \\
\hline 0 & $6(2.5 \%)$ \\
\hline । & $80(33.5 \%)$ \\
\hline$\|$ & $58(24.2 \%)$ \\
\hline III & $86(36.0 \%)$ \\
\hline IV & $9(3.8 \%)$ \\
\hline Postoperative hospital stay (days) & $\begin{array}{l}13 \pm 24.8 \\
\text { (range 6-284) }\end{array}$ \\
\hline
\end{tabular}


are categorized according to the Clavien-Dindo classification system [10]. If a patient had more than one complication, then the grade used for analysis was determined by the highest ranked complication. Complications of grades I-II were defined as minor complications, whereas those of grades III-V were considered as major complications.

\section{Follow-up}

Complete follow-up data were available for all patients followed with a standardized protocol at our institution. The duration of follow-up was calculated from the date of surgery. Follow-up data were collected from telephone records and records in the outpatient clinical database obtained after discharge. The end of the followup period was 3 years after surgery or death. Overall survival (OS) time was defined as the interval from the date of surgery to the date of death or that from the date of surgery to the date of the last follow-up examination for patients who remained alive. Disease-free survival (DFS) time was defined as the time period from surgery to date of relapse or distal metastasis.

\section{Statistical analysis}

All statistical analyses were conducted using SPSS for Windows version 22.0 (Chicago, IL, USA). Categorical variables were analyzed using chi-square or Fisher's exact test. Independent risk factors for complications were identified using binary logistic regression. The 3-year OS and DFS rates were calculated using the Kaplan-Meier method. The log-rank test was used to compare between the groups. Multivariate analyses were conducted using the Cox proportional hazards model. All tests were twosided, and $p<0.05$ was considered statistically significant difference.

\section{Results}

Patient demographics and surgical outcomes

Demographic and clinical characteristics of patients recruited in this study are shown in Table 2. The type and severity of postoperative complications are shown in Table 3. Overall, complications occurred in $59(24.7 \%)$ cases, and the mortality rate was $0.8 \%$ (2/ 239). Incidences of minor (grades I-II) and major (grades III-V) complications were 9.2\% (22/239) and $15.5 \%$ (37/239), respectively. The most frequent complication was anastomotic leakage (18/239, 7.5\%), followed by gastric stasis $(10 / 239,4.2 \%)$ and abdominal bleeding $(6 / 239,2.5 \%)$. Twelve patients required surgical management. Two patients died from postoperative complications-one patient died at 11 days after surgery because of an uncontrollable postoperative infection, and the other patient died after 4 months following the deterioration of postoperative gastric stasis.

\section{Risk factors associated with complications}

Patients were divided into the complication (C group) and no-complication (NC group) groups. As shown in Table 4, there was no significant difference between the $\mathrm{C}$ group and NC group in terms of sex, comorbidity, a prior history of abdominal surgery, preoperative chemotherapy, the extent of resection (total vs. subtotal), or the type of surgery (open vs. laparoscopic). The development of postoperative complications was associated with age $>55$ years, BMI $\geq$ 25 , operation time $>200 \mathrm{~min}$, and combined organ resection $(p<0.05)$. Further multivariate analysis identified age, BMI, operation time, and combined organ resection as independent risk factors for the development of postoperative complications (Table 5).

Table 3 Details of postoperative complications following gastrectomy

\begin{tabular}{|c|c|c|c|c|c|c|c|c|}
\hline \multirow[t]{2}{*}{ Type of complication } & \multicolumn{7}{|c|}{ Grade according to the Clavien-Dindo classification } & \multirow[t]{2}{*}{ Total } \\
\hline & I & $\|$ & IIla & $\| l \mid b$ & IVa & $\mathrm{IVb}$ & V & \\
\hline Anastomotic leakage & & 2 & 11 & 3 & 1 & & 1 & 18 \\
\hline Anastomotic bleeding & & 1 & 2 & 1 & & & & 4 \\
\hline Abdominal bleeding & & 3 & 1 & 2 & & & & 6 \\
\hline Wound infection & 2 & 3 & & & & & & 5 \\
\hline Intestinal obstruction & 4 & & & 1 & & & & 5 \\
\hline Gastric stasis & & 3 & 6 & & & & 1 & 10 \\
\hline Duodenal stump leakage & & 1 & & 1 & 1 & & & 3 \\
\hline Abdominal effusion & & & 3 & & & & & 3 \\
\hline Pancreatitis & & & & 1 & & & & 1 \\
\hline Bowel perforation & & & & 1 & & & & 1 \\
\hline Pneumonia & & 3 & & & & & & 3 \\
\hline Total & 6 & 16 & 23 & 10 & 2 & 0 & 2 & 59 \\
\hline
\end{tabular}


Table 4 Univariate analysis for risk factors associated with complications following gastrectomy

\begin{tabular}{|c|c|c|c|}
\hline Variables & $\begin{array}{l}\text { No complication } \\
n=180\end{array}$ & $\begin{array}{l}\text { Complication } \\
n=59\end{array}$ & $P$ value \\
\hline Sex & & & 0.325 \\
\hline Male & $122(67.8)$ & $44(74.6)$ & \\
\hline Female & $58(32.2)$ & $15(25.4)$ & \\
\hline Age & & & 0.029 \\
\hline$\leq 55$ & $71(39.4)$ & $14(23.7)$ & \\
\hline$>55$ & $109(60.6)$ & $45(76.3)$ & \\
\hline BMI & & & 0.027 \\
\hline$<25$ & $134(74.4)$ & $35(59.3)$ & \\
\hline$\geq 25$ & $46(25.6)$ & $24(40.7)$ & \\
\hline Operation time (min) & & & 0.018 \\
\hline$\leq 200$ & $80(44.4)$ & $16(27.1)$ & \\
\hline$>200$ & $100(55.6)$ & $43(72.9)$ & \\
\hline Resection type & & & 0.242 \\
\hline Subtotal & $89(49.4)$ & $24(40.7)$ & \\
\hline Total & $91(50.6)$ & $35(59.3)$ & \\
\hline Combined organ resection & & & 0.016 \\
\hline Yes & $4(2.2)$ & $6(10.2)$ & \\
\hline No & $176(97.8)$ & $53(89.8)$ & \\
\hline Neoadjuvant chemotherapy & & & 0.136 \\
\hline Yes & $60(33.3)$ & $26(44.1)$ & \\
\hline No & $120(66.7)$ & $33(55.9)$ & \\
\hline Surgery type & & & 0.877 \\
\hline Open & $157(87.2)$ & $51(86.4)$ & \\
\hline Laparoscope & $23(12.8)$ & $8(13.6)$ & \\
\hline Comorbidity Diabetes & & & 0.160 \\
\hline Yes & $11(6.1)$ & $7(11.9)$ & \\
\hline No & $169(93.9)$ & $52(88.1)$ & \\
\hline Cardiovascular Diseases & & & 0.606 \\
\hline Yes & $36(20.0)$ & $10(16.9)$ & \\
\hline No & $144(80.0)$ & 49 (83.1) & \\
\hline Prior abdominal surgery & & & 0.135 \\
\hline Yes & $20(11.1)$ & $11(18.6)$ & \\
\hline No & $160(88.9)$ & 48 (81.4) & \\
\hline
\end{tabular}

\section{Complication and survival}

Median survival during the follow-up period was 36.3 months. The 3 -year OS $(p=0.033)$ and DFS $(p=0.034)$ rates were significantly better in the $\mathrm{NC}$ group than in the $\mathrm{C}$ group (Fig. 1). To determine the types of complications that had the greatest impact on survival, the effects of major (CD grade III or higher) and infectious complications were analyzed.

In our study, major complications were those that were Clavien-Dindo grade III or higher. Patients without major
Table 5 Multivariate analysis for risk factors associated with complications following gastrectomy

\begin{tabular}{|c|c|c|c|}
\hline Variables & Hazard ratio & $95 \% \mathrm{Cl}$ & $P$ value \\
\hline \multicolumn{4}{|l|}{ Age } \\
\hline$\leq 55$ vs. $>55$ & 2.392 & $1.184-4.832$ & 0.015 \\
\hline \multicolumn{4}{|l|}{ BMl } \\
\hline$<25$ vs. $\geq 25$ & 2.124 & $1.110-4.062$ & 0.023 \\
\hline \multicolumn{4}{|c|}{ Operation time (min) } \\
\hline$\leq 200$ vs. $>200$ & 2.066 & $1.060-4.029$ & 0.033 \\
\hline
\end{tabular}

Combined organ resection

$\begin{array}{llll}\text { Yes vs. no } & 4.334 & 1.113-16.876 & 0.034\end{array}$

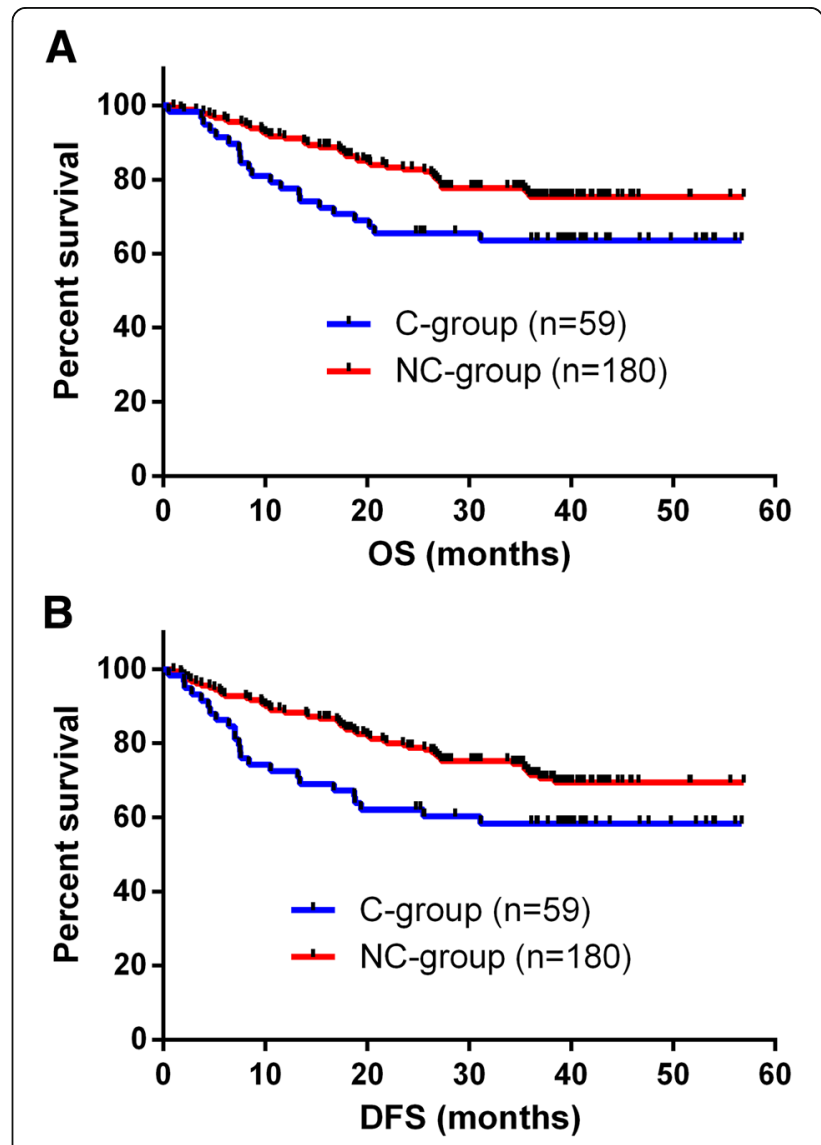

Fig. 1 a Overall survival curves for 239 patients who underwent curative gastrectomy for gastric cancer. The 3 -year overall survival rate is significantly better in the NC group than in the $C$ group ( $p=$ 0.033). b Disease-free survival curves for 239 patients who underwent curative gastrectomy for gastric cancer. The 3-year disease-free survival rate is significantly better in the group of patients without complications than in the group with complications $(p=0.034)$ 


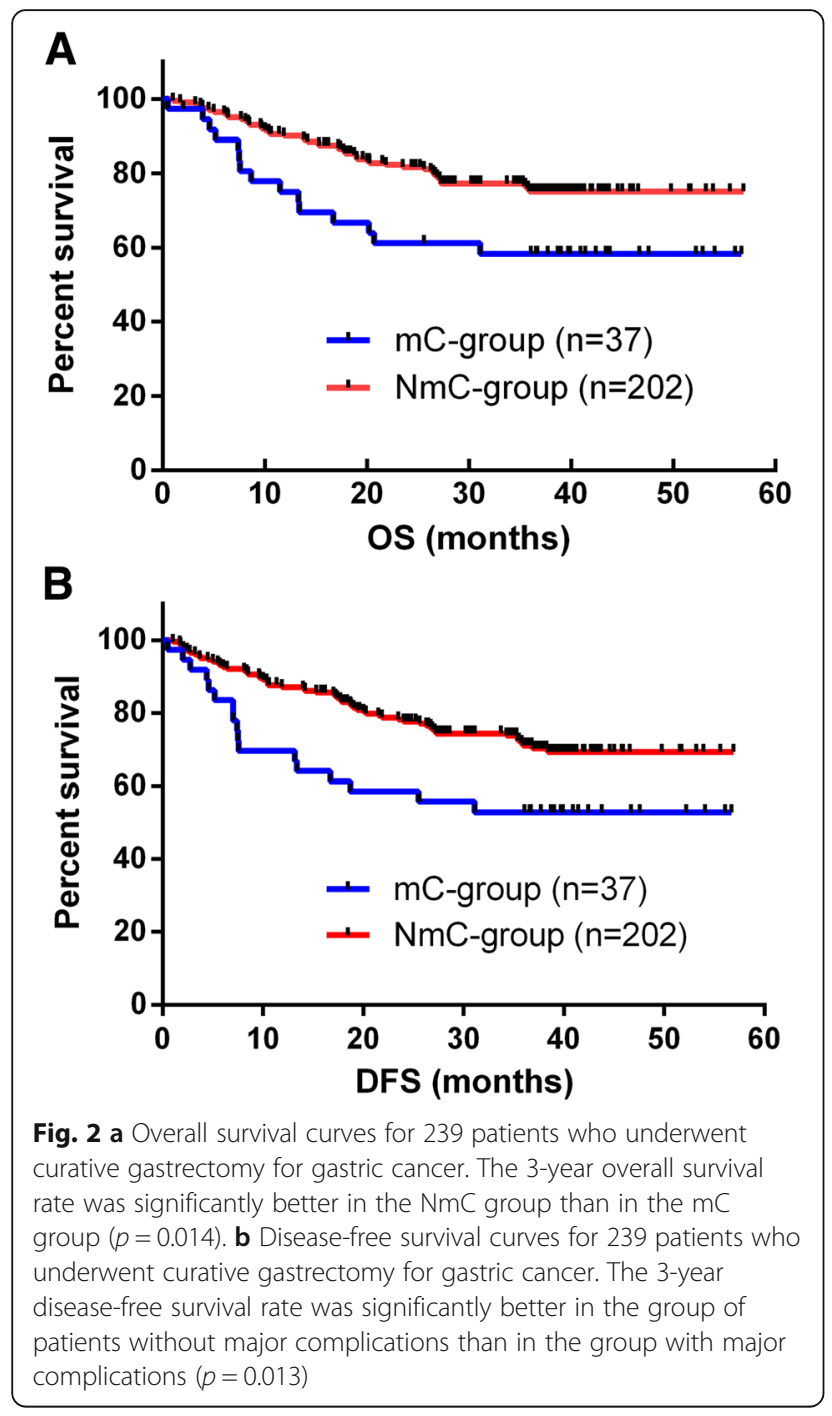

complications (NmC group) had significantly better 3 -year OS $(p=0.014)$ and DFS $(p=0.013)$ rates than those with major complications (Fig. 2). Results of multivariate analysis revealed that major complications and advanced TNM stage were independent risk factors for decreased 3-year OS and DFS rates in patients with gastric cancer who had undergone D2 gastrectomy (Table 6).

This study included 30 cases of infectious complications, including 18 cases of anastomotic leakage, 3 cases of duodenal stump leakage, 5 cases of surgical site infection, 1 case of bowel perforation, and 3 cases of pneumonia. We further analyzed the data and found that patients without infectious complications ( $\mathrm{NiC}$ group) had significantly better 3-years OS $(p<0.001)$ and DFS $(p=0.001)$, compared with patients who had infectious complications (Fig. 3). The survival analysis showed that having infectious complications and higher TNM stage were independent risk factors for poorer OS and DFS (Table 7).

Further subgroup analysis showed that, among stage II patients, major complications were associated with poorer 3 -year OS and DFS rates $(p=0.001$ and $p=0.003$, respectively; Fig. 4). The multivariate analysis also identified major complications as an independent prognostic factor for OS and DFS in the subgroup of patients with stage II gastric cancer (Table 8).

\section{Discussion}

Postoperative complications, especially surgical complications, significantly prolong hospital stay and medical expenditure, and impair short-term survival after surgery, with possible negative impacts on long-term survival. In this study, we analyzed medical records for consecutive gastric cancer cases seen during the period from 2012 to 2013 . We confirmed poorer long-term survival in patients with postoperative complications. Subsequent analyses confirmed that major complications and infectious complications are major causes of impaired long-term survival.

Table 6 Results of multivariate analysis to identify independent prognostic factors for overall survival and disease-free survival (major complication)

\begin{tabular}{|c|c|c|c|c|c|c|}
\hline \multirow[t]{2}{*}{ Variables } & \multicolumn{2}{|l|}{ OS } & \multirow[t]{2}{*}{$P$ value } & \multicolumn{2}{|l|}{ DFS } & \multirow[t]{2}{*}{$P$ value } \\
\hline & Hazard ratio & $95 \% \mathrm{Cl}$ & & Hazard ratio & $95 \% \mathrm{Cl}$ & \\
\hline TNM staging & 3.426 & $2.275-5.161$ & $<0.001$ & 3.315 & $2.330-4.717$ & $<0.001$ \\
\hline \multicolumn{7}{|c|}{ Introvascular cancer emboli } \\
\hline Yes vs. no & 1.365 & $0.808-2.306$ & 0.244 & 1.215 & $0.754-1.959$ & 0.423 \\
\hline \multicolumn{7}{|c|}{ Combined organ resection } \\
\hline Yes vs. no & 1.431 & $0.625-3.275$ & 0.397 & 1.531 & $0.687-3.410$ & 0.298 \\
\hline \multicolumn{7}{|l|}{ Resection type } \\
\hline Subtotal vs. Total & 1.559 & $0.862-2.820$ & 0.141 & 1.482 & $0.868-2.530$ & 0.15 \\
\hline \multicolumn{7}{|l|}{ Major complication } \\
\hline Yes vs. no & 1.939 & $1.056-3.561$ & 0.033 & 1.947 & $1.18-3.391$ & 0.019 \\
\hline
\end{tabular}




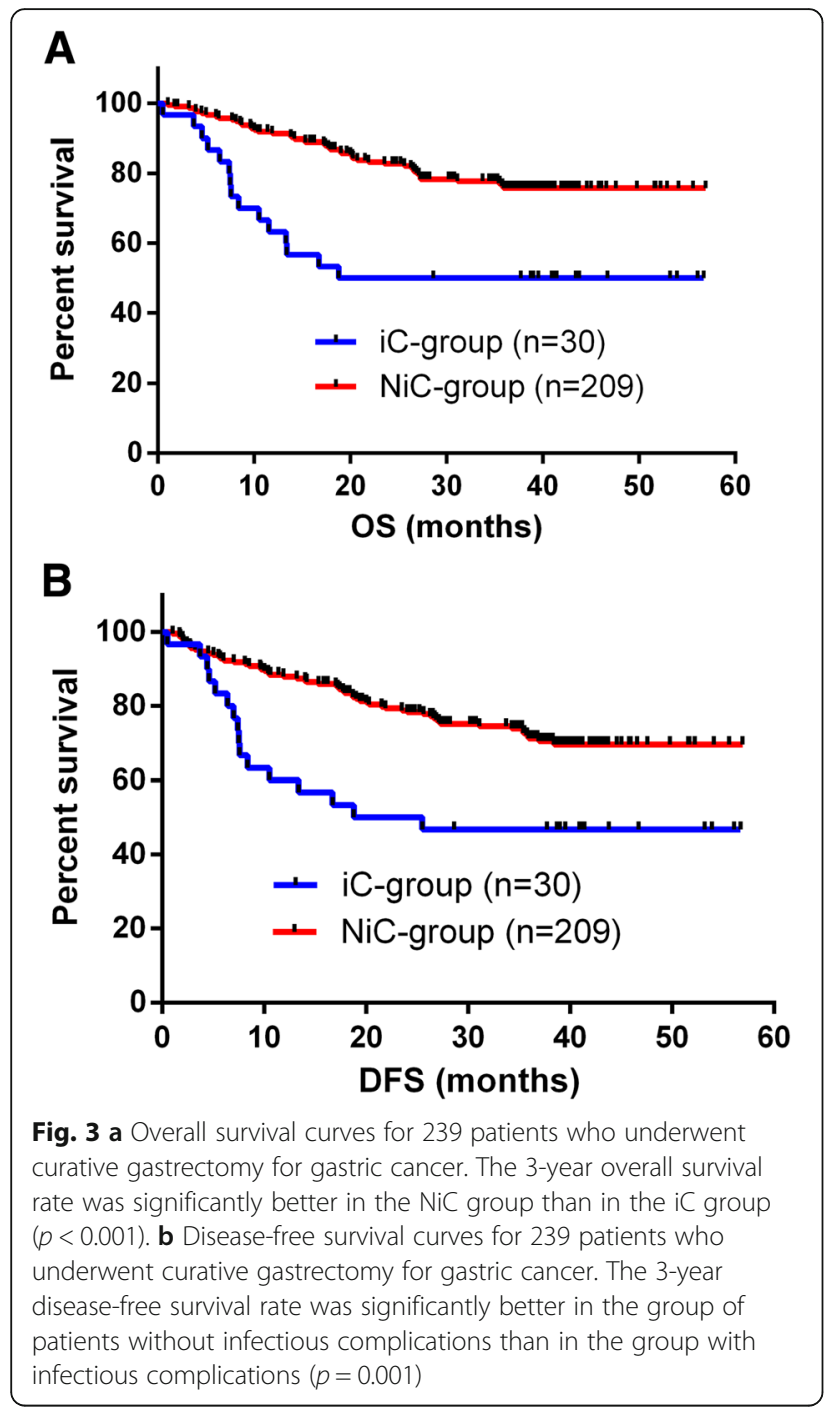

The topic of "complication and survival" has been examined repeatedly, with controversial results. Several studies have reported a correlation between postoperative complications and poor long-term outcome among patients with esophageal or gastroesophageal cancer [6, 11, 12]. Among patients with colorectal cancer, postoperative complications are associated with a higher rate of recurrence and worse long-term outcomes [13-15]. Branagan and Finnis reported that rectal anastomosis leakage, compared with colonic anastomosis leakage, increased the risk of local recurrence after colorectal surgery. However, the same authors reported no difference in long-term survival between patients with vs. without anastomotic leakage [8]. A similar result was reported by Junemann-Ramirez et al. who found that anastomotic leakage did not shorten 5-year survival in patients undergoing esophagogastrectomy, though 30-day mortality was much higher in the group with anastomotic leakage [16].

One possible explanation for this controversial data is that only severe complications (CD grade III or higher), but not minor complications (CD grade I-II), impair patient survival. We performed subgroup analysis, the results of which confirmed poorer survival in patients with major complications.

Most theories attribute poorer survival in patients with complications to the local recurrence or distant metastasis of cancer $[7,17,18]$. In patients who undergo colorectal resection, long-term outcomes may be severely impaired when anastomotic leakage occurs $[14,15]$. It has been proposed that anastomotic leakage leads to the deposition and implantation of viable exfoliated tumor cells in the pelvis, which results in an increased rate of local recurrence [13]. However, in their study, Tokunaga et al. did not observe local recurrence in any patient with anastomotic leakage [7].

With regard to infectious complications such as intra-abdominal abscess, abdominal infection, and pneumonia, the poorer survival observed in our study and in previous

Table 7 Results of multivariate analysis to identify independent prognostic factors for overall survival and disease-free survival (infectious complication)

\begin{tabular}{|c|c|c|c|c|c|c|}
\hline \multirow[t]{2}{*}{ Variables } & \multicolumn{2}{|l|}{ OS } & \multirow[t]{2}{*}{$P$ value } & \multicolumn{2}{|l|}{ DFS } & \multirow[t]{2}{*}{$P$ value } \\
\hline & Hazard ratio & $95 \% \mathrm{Cl}$ & & Hazard ratio & $95 \% \mathrm{Cl}$ & \\
\hline TNM staging & 3.284 & $2.199-4.903$ & $<0.001$ & 3.197 & $2.256-4.529$ & $<0.001$ \\
\hline \multicolumn{7}{|c|}{ Introvascular cancer emboli } \\
\hline Yes vs. no & 1.327 & $0.782-2.252$ & 0.294 & 1.178 & $0.728-1.906$ & 0.504 \\
\hline \multicolumn{7}{|c|}{ Combined organ resection } \\
\hline Yes vs. no & 1.713 & $0.765-3.832$ & 0.19 & 1.662 & $0.751-3.676$ & 0.21 \\
\hline \multicolumn{7}{|l|}{ Resection type } \\
\hline Subtotal vs. Total & 1.464 & $0.802-2.671$ & 0.214 & 1.449 & $0.844-2.488$ & 0.179 \\
\hline \multicolumn{7}{|c|}{ Infectious complication } \\
\hline Yes vs. no & 2.47 & $1.346-4.533$ & 0.004 & 1.935 & $1.083-3.457$ & 0.026 \\
\hline
\end{tabular}




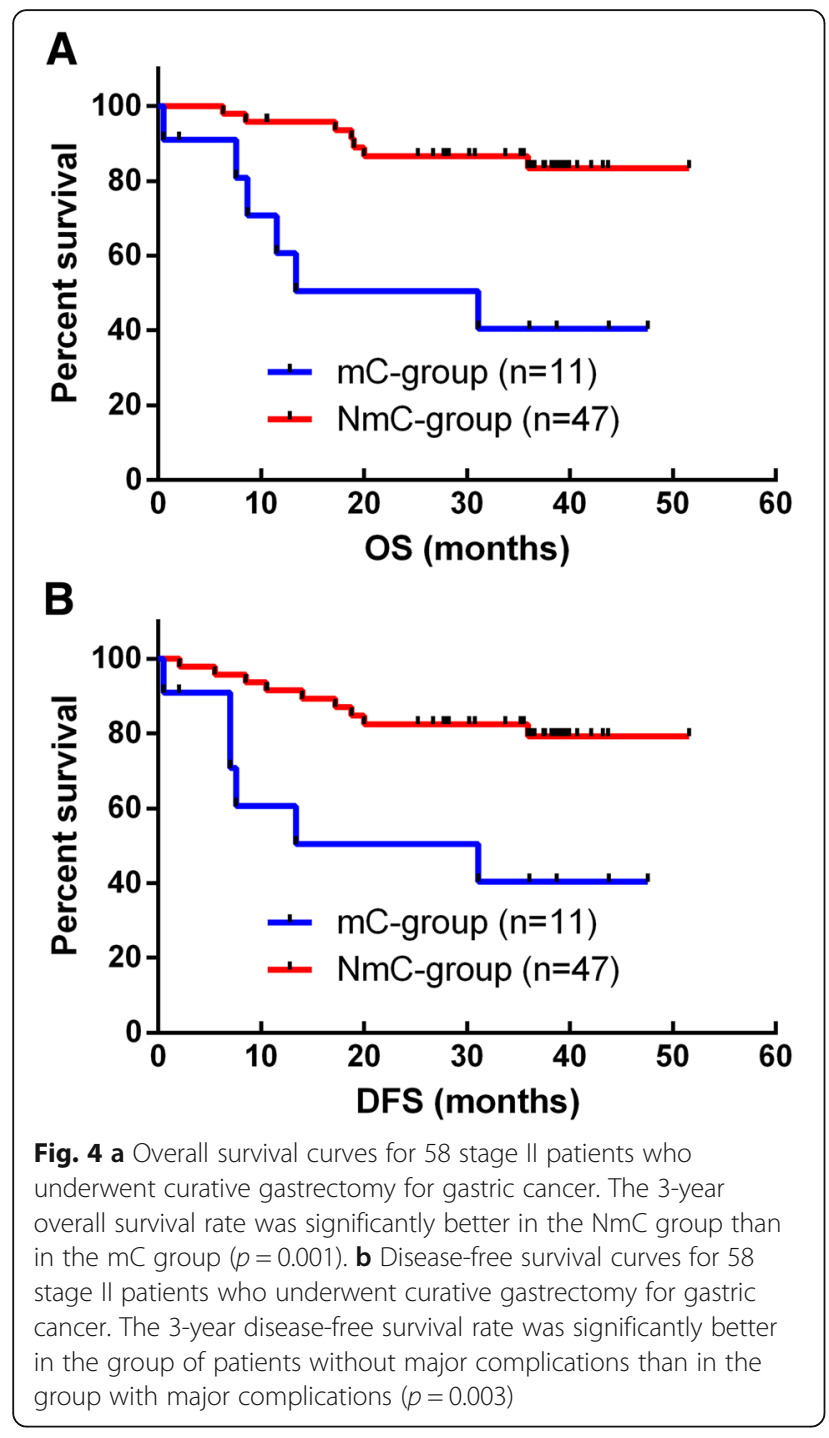

Table 8 Results of multivariate analysis to identify independent prognostic factors for overall survival and disease-free survival in the subgroup of II stage gastric cancer

\begin{tabular}{|c|c|c|c|c|c|c|}
\hline \multirow[t]{2}{*}{ Variables } & \multicolumn{2}{|l|}{ OS } & \multirow{2}{*}{$\begin{array}{l}P \\
\text { value }\end{array}$} & \multicolumn{2}{|l|}{ DFS } & \multirow{2}{*}{$\begin{array}{l}P \\
\text { value }\end{array}$} \\
\hline & Hazard ratio & $95 \% \mathrm{Cl}$ & & Hazard ratio & $95 \% \mathrm{Cl}$ & \\
\hline \multicolumn{7}{|c|}{ Introvascular cancer emboli } \\
\hline Yes vs. no & 0.439 & $0.092-2.093$ & 0.301 & 0.37 & $0.08-1.715$ & 0.204 \\
\hline \multicolumn{7}{|c|}{ Combined organ resection } \\
\hline Yes vs. no & 1.48 & $0.173-12.684$ & 0.72 & 1.224 & $0.149-10.077$ & 0.851 \\
\hline \multicolumn{7}{|l|}{ Resection type } \\
\hline Subtotal vs. Total & 1.125 & $0.356-3.557$ & 0.841 & 1.024 & $0.354-2.962$ & 0.965 \\
\hline \multicolumn{7}{|l|}{ Major complication } \\
\hline Yes vs. no & 5.667 & $1.842-17.439$ & 0.002 & 4.34 & $1.498-12.571$ & 0.007 \\
\hline
\end{tabular}

investigations may reflect immune suppression that results in cancer recurrence and poorer survival $[19,20]$. Postoperative infections induce proinflammatory cytokine cascades. Inflammatory cytokines such as tumor necrosis factoralpha (TNF- $\alpha$ ) and interleukins 1, 6 and 8 (IL-1/6/8) may interfere with the function of natural killer cells, cytotoxic T-lymphocytes, and antigen-presenting cells [21-23], which promote the growth and metastasis of tumor cells. Postoperative infections also delay the initial date of adjuvant chemotherapy after surgery, which may further diminish survival $[24,25]$.

One advantage of our study is the fact that our database is prospectively maintained. Furthermore, all data related to the incidence of complications were double checked and recorded by the chief resident, who was very familiar with the perioperative condition of each patient. The second check also minimized possible bias among researchers. After the above-mentioned efforts, our recorded complication rates were comparable to those of many high-quality databases [3-5].

Further subgroup analysis showed that major complications were an independent prognostic factor for OS and DFS in the subgroup with stage II gastric cancer. In this study, the mean duration of postoperative hospital stay was 11.9 (6-24) days among patients without postoperative complications and 38.1 (8-284) days among those with postoperative complications $(p<$ 0.0001). Perhaps patients with major complications delayed or were unable to undergo chemotherapy. Major complications may therefore be considered as a strong risk factor for decreased OS and DFS in stage II patients. Additional studies with larger, multicenter, randomized prospective cohorts should be performed to verify these findings.

Given the fact that complications significantly compromise postoperative survival, we further identified factors that increase risk for complications by analyzing patient characteristics and perioperative parameters. However, in our database, the only adjustable factor 
identified was BMI. Operation time and combined organ resection were mainly associated with tumor stage and technical difficulty. In such circumstances, the prevention and early diagnosis of complications are of critical importance.

The limitations of the present study were its retrospective nature and relatively small sample population. There was a lack of information pertaining to postoperative chemotherapy, which may have affected patient overall survival, but lack of information about chemotherapy maybe didn't affect the DFS outcomes. The reason that all the patients received standard radical D2 gastrectomy and majority of patients received standard chemotherapy after surgery, the chemotherapy drugs include Oxaliplatin, Xeloda, S-1, Paclitaxel, etc., there maybe no treatment changed before tumor relapse. In our findings, we found the 3-year disease-free survival rate is significantly better in the group of patients without complications than in the group with complications, this trend was also observed in the major or infectious complications group. Further subgroup analysis showed that, among stage II patients, major complications were associated with poorer 3-year DFS rates, Despite these limitations, we believe that major complications are an important and adverse prognostic indicator in patients with gastric cancer.

\section{Conclusion}

Our data confirmed a survival disadvantage in patients with postoperative complications after gastric cancer surgery, with the effect being more profound for cases with major and/or infectious complications. Prevention and early diagnosis of complications are essential to minimize the influence of complications on surgical safety and patient survival.

\section{Abbreviations}

BMI: Body mass index; DFS: Disease-free survival; OS: Overall survival

\section{Acknowledgements}

We appreciate the hard work of the colleagues at the database center of our hospital who helped us reserve and search the relative data. Also, thank you for enago editing service.

\section{Authors' contributions}

As the leading principle investigator of the study, JJ and ZL contributed significantly to the study design, data analysis, interpretation of the data, critical evaluation, and clinical management; all authors were involved in developing the original study and protocols. PY and ZW contributed to data analysis and drafting of the manuscript. ZB, AW, XW, LZ, JS were responsible for patient enrolment and interpretation of the data. All authors provided significant input to the paper by means of revisions and all have read and approved the final manuscript.

\section{Funding}

This study was funded by the Beijing Municipal Administration of Hospital Clinical Medicine Development of Special Funding Support (ZYLX201701) and Supported by the Beijing Municipal Training for the Talents (2016000021469G190). The funder was not involved in designing the study, collecting or analysing the data, or preparing the manuscript.

\section{Availability of data and materials}

The datasets used and analysed during the current study are available from the corresponding author on reasonable request.

\section{Ethics approval and consent to participate}

This study was conducted in accordance with the Declaration of Helsinki and had been authorized by the Ethics Committee of Peking University Cancer Hospital (Reference No. 2017KT37) before beginning the study. Each patient in this study provided signed informed consent.

\section{Consent for publication}

Not applicable.

\section{Competing interests}

The authors declare that they have no competing interests.

\section{Author details}

${ }^{1}$ Key Laboratory of Carcinogenesis and Translational Research (Ministry of Education), Department of Endoscopy Center, Peking University Cancer Hospital \& Institute, \#52, Fucheng Road, Haidian, Beijing, People's Republic of China. ${ }^{2}$ Key Laboratory of Carcinogenesis and Translational Research (Ministry of Education), Department of Gastrointestinal Cancer Center Surgery, Peking University Cancer Hospital \& Institute, \#52, Fucheng Road, Haidian, Beijing, People's Republic of China.

Received: 19 November 2018 Accepted: 8 August 2019

Published online: 23 August 2019

\section{References}

1. Bray F, Ferlay J, Soerjomataram I, et al. Global cancer statistics 2018: GLOBOCAN estimates of incidence and mortality worldwide for 36 cancers in 185 countries. CA Cancer J Clin. 2018;68(6):394-424.

2. Songun I, Putter H, Kranenbarg EM, et al. Surgical treatment of gastric cancer: 15-year follow-up results of the randomised nationwide Dutch D1D2 trial. Lancet Oncol. 2010:11:439-49.

3. Watanabe M, Miyata $\mathrm{H}$, Gotoh $\mathrm{M}$, et al. Total gastrectomy risk model: data from 20,011 Japanese patients in a nationwide internet-based database. Ann Surg. 2014;260:1034-9.

4. Kurita N, Miyata H, Gotoh M, et al. Risk model for distal gastrectomy when treating gastric cancer on the basis of data from 33,917 Japanese patients collected using a nationwide web-based data entry system. Ann Surg. 2015; 262:295-303.

5. Bartlett EK, Roses RE, Kelz RR, et al. Morbidity and mortality after total gastrectomy for gastric malignancy using the American College of Surgeons National Surgical Quality Improvement Program database. Surgery. 2014; 156:298-304.

6. Hirai T, Yamashita Y, Mukaida $H$, et al. Poor prognosis in esophageal cancer patients with postoperative complications. Surg Today. 1998;28:576-9.

7. Tokunaga M, Tanizawa $Y$, Bando E, et al. Poor survival rate in patients with postoperative intra-abdominal infectious complications following curative gastrectomy for gastric cancer. Ann Surg Oncol. 2013;20:1575-83.

8. Branagan G, Finnis D, Wessex Colorectal Cancer Audit Working G. Prognosis after anastomotic leakage in colorectal surgery. Dis Colon Rectum. 2005;48:1021-6.

9. Kubota T, Hiki N, Sano T, et al. Prognostic significance of complications after curative surgery for gastric cancer. Ann Surg Oncol. 2014;21:891-8.

10. Clavien PA, Barkun J, de Oliveira ML, et al. The Clavien-Dindo classification of surgical complications: five-year experience. Ann Surg. 2009;250:187-96.

11. Rizk NP, Bach PB, Schrag D, et al. The impact of complications on outcomes after resection for esophageal and gastroesophageal junction carcinoma. J Am Coll Surg. 2004;198:42-50.

12. Lerut T, Moons J, Coosemans W, et al. Postoperative complications after transthoracic esophagectomy for cancer of the esophagus and gastroesophageal junction are correlated with early cancer recurrence: role of systematic grading of complications using the modified Clavien classification. Ann Surg. 2009:250:798-807.

13. Bell SW, Walker KG, Rickard MJ, et al. Anastomotic leakage after curative anterior resection results in a higher prevalence of local recurrence. $\mathrm{Br} J$ Surg. 2003;90:1261-6. 
14. Law WL, Choi HK, Lee YM, et al. Anastomotic leakage is associated with poor long-term outcome in patients after curative colorectal resection for malignancy. J Gastrointest Surg. 2007;11:8-15.

15. Walker KG, Bell SW, Rickard MJ, et al. Anastomotic leakage is predictive of diminished survival after potentially curative resection for colorectal cancer. Ann Surg. 2004;240:255-9.

16. Junemann-Ramirez M, Awan MY, Khan ZM, Rahamim JS. Anastomotic leakage post-esophagogastrectomy for esophageal carcinoma: retrospective analysis of predictive factors, management and influence on longterm survival in a high volume centre. Eur J Cardiothorac Surg. 2005;27:3-7.

17. Li QG, Li P, Tang D, et al. Impact of postoperative complications on longterm survival after radical resection for gastric cancer. World J Gastroenterol. 2013;19:4060-5

18. Slankamenac K, Slankamenac M, Schlegel A, et al. Impact of postoperative complications on readmission and long-term survival in patients following surgery for colorectal cancer. Int J Color Dis. 2017;32:805-11.

19. Mantovani A, Allavena P, Sica A, Balkwill F. Cancer-related inflammation. Nature. 2008;454:436-44.

20. Goldfarb Y, Sorski L, Benish M, et al. Improving postoperative immune status and resistance to cancer metastasis: a combined perioperative approach of immunostimulation and prevention of excessive surgical stress responses. Ann Surg. 2011;253:798-810.

21. Balkwill F, Mantovani A. Inflammation and cancer: back to Virchow? Lancet. 2001;357:539-45.

22. Menetrier-Caux C, Montmain G, Dieu MC, et al. Inhibition of the differentiation of dendritic cells from CD34(+) progenitors by tumor cells: role of interleukin-6 and macrophage colony-stimulating factor. Blood. 1998; 92:4778-91.

23. Horn F, Henze C, Heidrich K. Interleukin-6 signal transduction and lymphocyte function. Immunobiology. 2000;202:151-67.

24. Czaykowski PM, Gill S, Kennecke HF, et al. Adjuvant chemotherapy for stage III colon cancer: does timing matter? Dis Colon Rectum. 2011;54:1082-9.

25. Bayraktar UD, Chen E, Bayraktar S, et al. Does delay of adjuvant chemotherapy impact survival in patients with resected stage II and III colon adenocarcinoma? Cancer. 2011;117:2364-70.

\section{Publisher's Note}

Springer Nature remains neutral with regard to jurisdictional claims in published maps and institutional affiliations.

Ready to submit your research? Choose BMC and benefit from:

- fast, convenient online submission

- thorough peer review by experienced researchers in your field

- rapid publication on acceptance

- support for research data, including large and complex data types

- gold Open Access which fosters wider collaboration and increased citations

- maximum visibility for your research: over $100 \mathrm{M}$ website views per year

At $\mathrm{BMC}$, research is always in progress.

Learn more biomedcentral.com/submissions 